\title{
Refractory Epistaxis: Role of Endoscopic Cauterisation of Sphenopalatine Artery
}

\author{
Dharmendra Verma ${ }^{1}$, Shubham Agarwal ${ }^{2}$ \\ ${ }^{1,2}$ Senior Resident, ENT Department, SMS Medical College and Hospital, Jaipur, India
}

\begin{abstract}
Epistaxis is defined as bleeding from the nose. It is one of the most common rhinological emergencies, making the management of posterior epistaxis a challenging problem for ENT surgeons. Conventional management options in form of chemical cauterisation, anterior nasal packing and posterior nasal packing, are not so much effective and satisfactory. Objective: The objective of this study was to assess the effectiveness of endoscopic sphenopalatine artery (SPA) cauterization in patients with refractory epistaxis. Materials and Method: The experience of endoscopic sphenopalatine artery cauterisation under general anaesthesia in 3 patients has been described. All patients had undergone anterior nasal packing, posterior nasal packing, endoscopic cauterisation of visible bleeding points but all of them failed to control bleeding. Results: Epistaxis was controlled in all the 3 patients after endoscopic sphenopalatine artery cauterisation. Discussion: Endoscopic sphenopalatine artery cauterisation is a safe and effective method of managing refractory posterior nasal bleeding which is not responding to all other conservative measures.
\end{abstract}

Keywords: Sphenopalatine artery, endoscopic cauterization, epistaxis.

\section{Introduction}

Epistaxis is one of the most common emergencies in ENT department. There is a bimodal distribution with peaks in children and young adults and the older adult ( $45-65$ years). ${ }^{1}$ Sometimes it may be intractable and challenging for ENT surgeon. It may be life threatening because of associated complications like aspiration, hypotension and anaemia. ${ }^{2}$ Most cases of epistaxis can be managed with conservative measures like nasal packings and chemical cautery. Upto $15 \%$ of patients require hospital admission for some surgical intervention.

Previously ligation of internal maxillary artery was considered through trans-antral route. However it may be associated with many major complications like facial swelling, facial nunbness, oro-antral fistula and failure rate of $10-15$ percent. ${ }^{3}$ More recently cauterisation or clipping has been adopted which is safe and not associated with any major complication.

In this study, we have tried to control refractory epistaxis via cauterizing the sphenopalatine artery endoscopically.

\section{Materials and Methods}

A yearlong prospective study was carried out in our institution. All patients had persistant epistaxis despite several episodes of anterior and posterior nasal packing in form of conservative management. Patients underwent Sphenopalatine artery cauterization following an informed consent. Mean time of patient follow up was 6 months.

\section{Procedure}

Sphenopalatine artery cauterisation was done under general anaesthesia. Initially, nostril packed with nasal packings soaked in solution ssaline $(30 \mathrm{ml})+1: 100,000$ adrenaline $(2 \mathrm{ml})\}$.

Local anesthesia xylocaine $2 \% \quad(1 \mathrm{ml})$ with 1:100,000adrenaline was injected into the pterygopalatine fossa through the greater palatine foramen in the roof of the hard palate. Greater palatine foramen identified between second and third molar teeth $1 \mathrm{~cm}$ medial to this area. After this nasal packs removed, decongested and middle meatus antrostomy done. Mucoperiosteal flap elevated from posterior lip of antrum. Sphenopalatine artery identified running vertically approximately $1 \mathrm{~cm}$ behind the ostium.

Location of sphenopalatine foramen can be identified by the help of crista ethmoidalis. After identification of sphenopalatine artery, it was cauterised with endoscopic bipolar diathermy. Muco-periosteal flap repositioned and nasal packing done. Packing removed 72 hours after surgery.

Details of the patient who underwent SPA cauterisation-

\begin{tabular}{|c|c|c|c|}
\hline Age/Sex & Presentation & Side & Associated disease \\
\hline $75 / \mathrm{F}$ & $\begin{array}{c}\text { Recurrent epsitaxis } \\
\text { for 2 months }\end{array}$ & $\mathrm{B} / \mathrm{L}$ & Acquired haemophilia \\
\hline $21 / \mathrm{M}$ & $\begin{array}{c}\text { Recurrent epistaxis } \\
\text { for 4 months }\end{array}$ & Rt. & Trauma \\
\hline $35 / \mathrm{M}$ & $\begin{array}{c}\text { Recurrent epistaxis } \\
\text { for 2 months }\end{array}$ & Rt. & Idiopathic \\
\hline
\end{tabular}

\section{Results}

The procedure took around average 40 minutes. No immediate post-op complication was noted in any patient due to the procedure. Major bleeding was controlled except mild oozing from the mucosa. One patient who was diagnosed as acquired haemophilia expired ten days after the procedure due to hypovolaemic shock due to repeated haemorrhage from mucosal sites \& internal bleeding other than nose. It is to be noted that in this patient also SPA cauterization worked excellent and major nasal bleeding stopped just after the arterial cauterization. Other 2 patients didn't present with any active epistaxis episode in their 6 months follow-up. 


\section{International Journal of Science and Research (IJSR) \\ ISSN (Online): 2319-7064}

Index Copernicus Value (2013): 6.14 | Impact Factor (2014): 5.611

\section{Discussion}

In recent years, with advances in surgical technology, the advent of endoscopic sinus surgery has brought change in the treatment of sinus disease and has increased our knowledge of the anatomy of the lateral nasal wall.

The invention of the Hopkins rod in 1960s has revolutionised nasal surgery. Only recently has this new technology been adapted for the treatment of epistaxis. ${ }^{4-6}$

Traditionally the treatment options have included one or more of the following: nasal packing, septoplasty and arterial ligation of internal maxillary artery and external carotid artery or anterior ethmoidal artery. Apart from a high failure rate ranging from 26 to $52 \%$ and posterior nasal packing is associated with considerable discomfort and mucosal trauma, morbidity due to hypoxia. ${ }^{7}$

Repeated nasal packing has a high rate of complications (69\%), including synechia, sinusitis, lesions in the nasal mucosa, local infections, septal perforation, orbital cellulitis, necrosis of the nasal ala, fracture of the lamina papyracea, perforation of the palate, and alterations in the middle ear. Other possible complications, although very rare, include pyogenic granuloma, allergy, toxic shock syndrome, obstructive sleep apnea syndrome (OSAS), hypoventilation, chest pain, hypoxia, aspiration (if the tamponade is moved), altered arterial blood gases, bradycardia, hypotension, and infectious endocarditis ${ }^{8-12}$

Traditional arterial ligation methods are also associated with significant morbidity and failure rates. The transantral approach to the maxillary artery may cause damage to the nasolacrimal duct or infraorbital nerve and thus cheek anaesthesia. External carotid artery ligation is associated with risk of damage to hypoglossal nerve and vagus nerve. Moreover there is a high failure rate due to extensive anastomosis distal to the site of ligation. ${ }^{13}$

Sokoloff first undertook angiographic embolisation for epistaxis in 1972. ${ }^{14}$ Embolisation is routinely performed in some centres as a means of treating intractable epistaxis. The technique entails cannulation of the external carotid artery and location of the bleeding point by water soluble contrast. Coils, gel foam, and polyvinyl alcohol can then embolise the causative artery. The success rate has been reported to be as high as $87 \%$, which is similar to arterial ligation. ${ }^{15}$ The technique's limiting factors include; lack of specialist radiologists and equipment, the inability to embolise ethmoidal arteries because of the risk of blindness, false aneurysm development at the insertion site, cerebrovascular accidents, and imaging difficulties after nasal packing. Studies have reported a complication rate of $17 \%-27 \%{ }^{16}$

The microscopic surgical approach to the sphenopalatine foramen was first described by Prades (1978), ${ }^{17}$ as an approach for Vidian neurectomy. Subsequently, advances in techniques of nasal endoscopy, led to the sphenopalatine artery being accessed in the management of posterior epistaxis. This has resulted in the popularization of endoscopic cauterization of sphenopalatine artery in the management of refractory epistaxis.
One of the reasons that Sphenopalatine artery cauterization has become popular is that it is the terminal branch of the Internal Maxillary artery and is sufficiently distal to make retrograde and anastomotic blood flow from other vessels unlikely. This fact has led surgeons to consider how to better approach this artery in an attempt to minimize both morbidity and failure rates, despite the description of transantral routes to the sphenopalatine artery.$^{18}$

Buchwald and Jensen (2006) showed that this is a minimally invasive technique which is effective and significantly reduces the discomfort for the patient. ${ }^{19}$

Srinivasan et al(2000) had compared trans-nasal endoscopic sphenopalatine artery diathermy with conventional approaches and including septoplasty and nasal packing and external carotid artery ligation ${ }^{20}$. They found that the sphenopalatine artery diathermy group experienced a shorter hospital stay on average and they experienced no surgeryrelated complications. Prepageran and Krishnan (2003) showed that endo-nasal endoscopic coagulation of sphenopalatine artery is a safe and efficient method of controlling persistent posterior epistaxis with minimal complication. $^{21}$

In Sharp et al. (1997) elevated a mucosal flap over the sphenopalatine foramen and then used a transnasal endoscopic approach to apply either diathermy or clips to the sphenopalatine vessels in 10 patients with intractable epistaxis; they reported no treatment failures. ${ }^{22}$

Similarly, Pritikin et al. (1998) applied bipolar diathermy and hemostatic clips to the sphenopalatine vessels via a transnasal endoscopic route in 10 patients with intractable epistaxis and they also reported a success rate of $100 \%{ }^{23}$

Our study aimed at determining the advantages of SPA cauterization over other methods and assessing the immediate and late post-operative cessation of epistaxis as well as complications associated with the procedure.

The cauterization of the Sphenopalatine artery leads to considerable complications. In some studies, $33 \%$ of cases had increased nasal crusting following this procedure. Also palatal numbness was reported in $13 \%$ of cases. However, in our study, no patient reported any of these complications. Sphenopalatine artery cauterization has been shown to be associated with a shorter hospital stay and cost effectiveness compared with other surgical modalities. There are no contraindications for sphenopalatine cauterization. Thus we recommend the use of this procedure for the control of posterior epistaxis as an immediate second-line management when conservative treatment as first line fails.

\section{Conclusion}

Endoscopic cauterization of SPA is technically straightforward to perform and allows direct cauterization of the major vessel supplying the posterior nasal cavity. The procedure appears to be safe, simple, fast, and effective for the management of refractory posterior epistaxis with low rates of morbidity and complications, and should be considered as an immediate second-line management when 


\section{International Journal of Science and Research (IJSR) \\ ISSN (Online): 2319-7064 \\ Index Copernicus Value (2013): 6.14 | Impact Factor (2014): 5.611}

conservative treatment as first line fails. Some experts even recommend its use as a first option, without waiting for the failure of posterior packing.

\section{References}

[1] Watkinson JC. Epistaxis. In: Mackay IS, Bull TR, eds. Scott Brown's otolaryngology. London: Butterworths, 1997; 18/5-7.2.

[2] Hadoura L, Douglas C, Mc Garry, Young D Mapping surgical navigation study. The journal of laryngology \& otology 2009; 123;742-5.

[3] Mc Donald TJ, Pearson BW, Follow up on maxillary artery ligation for epistaxis . Arch otolaryngol 1980; $106 ; 635-8$.

[4] Frikart L, Agrifoglio A. Endoscopic treatment of posterior epistaxis. Rhinology 1998;36:59-61.

[5] McGarry GW. Nasal endoscope in posterior epistaxis: a preliminary evaluation. J Laryngol Otol 1991;105:42831.

[6] Ahmed A, Woolford TJ. Endoscopic bipolar diathermy in the management of epistaxis: an effective and costefficient treatment. Clin Otolaryngol 2003;28:273-5.

[7] Shaw, C.B., M.K. Wax and S.J. Wetmore, 1993. Epistaxis: A comparison of treatment. Otolaryngol. Head Neck Surg, 109: 60-65.

[8] Agreda, Urpegui BA, Alfonso JI, Valles H. Ligation of the Sphenopalatine Artery in Posterior Epistaxis Retrospective Study of 50 Patients. Acta Otorrinolaringol Esp. 2011;62:194-8.

[9] Rudert H, Maune S. Endonasal coagulation of the sphenopalatine artery in severe posterior epistaxis. [German] Laryngo-Rhino-Otol. 1997;76:77-82.

[10] Simpson GT, Janfaza P, Becker GD. Transantral sphenopalatine

artery ligation. Laryngoscope. 1982;92(9: Pt 1):t-5.

[11] Srinivasan V, Sherman IW, O'Sullivan G. Surgical management of intractable epistaxis: audit of results. J Laryngol Otol. 2000:697-700.

[12] Tsai HM, Shu CH. Transnasal sphenopalatine artery electrocautery for posterior epistaxis. Chung Hua i Hsueh Tsa Chih - Chin Med J. 2002;65:529-33.

[13]Budrovich R, Saetti R. Microscopic and endoscopic ligature of the sphenopalatine artery. Laryngoscope. 1992;102:1390-1394.

[14] Sokoloff J, Wickbom I, McDonald D, et al. Therapeutic percutaneous embolization in intractable epistaxis. Radiology 1974;111:285-7.

[15] Vitek J. Idiopathic intractable epistaxis: endovascular therapy. Radiology 1991;181:113-16.

[16] Tseng EY, Narducci CA, Willing SJ, et al. Angiographic embolization for epistaxis: a review of 114 cases. Laryngoscope 1998;108:615-19.

[17] Pradesh J. endonasal de la fosse pterygo maxilaire. LXIII congress france: Rendus des séance;1980; 290-6.

[18] O'Flynn PE, Shadaba A. Management of posterior epistaxis by endoscopic clipping of the sphenopalatine artery. Clin Otolaryngol All Sci. 2000;25:374-7.

[19]Buchwald, C. and J. Jensen, 2006. Endoscopic sphenopalatine artery ligation or diathermy. Operat. Tech. Otolaryngol17:28-30. CrossRef
[20] Srinivasan, V., I.W. Sherrman and G. Sullivan, 2000. Surgical Management of intractable epistaxis: Audit of results. J. Laryngol. Otol., 114: 697-697.

[21] Prepageran, N. and G. Krishnan, 2003. Endoscopic coagulation of sphenopalatine artery for posterior epistaxis. Singapore Med. J., 44: 123-125.

[22] Sharp HR, Rowe jones J M, Biring G S, Mackay IS. Endoscopic ligation of diathermy of the sphenopalatine artery in persistant epistaxis. J Laryngol Otol 1997;111:1047-50.

[23] Pritkin JB,Calearelli DD, PanjeWR. Endoscopic ligation of the internal maxillary artery for treatment of intractable posterior epistaxis. ANN Otol Rhino Laryngol 1998;107:85-91

\section{Author Profile}

Shubham Agarwal, did his MBBS from Kasturba medical college, mangalore, Karnataka followed by M.S from KIMS, hubli, Karnataka. He has presented many papers both in state and national conferences and has been awarded a fellowship (FAGE) by the Manipal University. He was awarded a scholarship by ICMR (Indian Council of Medical Research) for conducting a research project. He is currently working as a senior resident in the department of ENT in SMS medical college, Jaipur, Rajasthan. 